\title{
One-Stage Laparo-Endoscopic Treatment of Cholecysto-Choledocholithiasis
}

\author{
HAMDY S. ABDALLAH, M.R.C.S., Ph.D.; SHERIF A. SABER, Ph.D. and MAHMOUD M. AL-SHAREEF, Ph.D. \\ The Department of General Surgery, Gastrointestinal and Laparoscopic Surgery Unit, Faculty of Medicine, \\ Tanta University, Egypt
}

\begin{abstract}
Introduction: Despite advances in both endoscopic and surgical therapeutics, the management of cholecystocholedocholithiasis continues to present a dilemma to both surgeons and gastroenterologists as a consensus on optimal management does not yet exist.
\end{abstract}

Patients and Methods: Patients with gallbladder stones and confirmed concomitant Common Bile Duct Stones (CBDS) were submitted to one-stage Laparoscopic Cholecystectomy (LC), Endoscopic Retrograde Cholangiography (ERC), endoscopic sphincterotomy and clearance of CBDS during the period from January 2009 to January 2017.

Results: The study included 200 patients with a median age of 45.3 years. Pre-operative work up confirmed the presence of CBDS in all patients. Five patients $(2.5 \%)$ were converted to open surgery. Intra-Operative Cholangiography (IOC) was performed in 185 patients $(94.9 \%)$ and it showed CBDS in 175 of them (94.6\%). Ten patients (5\%) with no stones on IOC had LC only. In 185 patients $(92.5 \%)$, LC plus ERC and endoscopic clearance of CBDS were completed successfully. The median total procedural time was 104 minutes and the median post-operative (PO) hospital stay was 1.5 days. Two patients $(1.1 \%)$ developed post-ERC bleeding. Liver function tests were normalized in all patients within 3 weeks PO. It was possible to re-assess all patients at 1 month and 160 patients $(86.5 \%)$ at 6 moths $\mathrm{PO}$ and all were symptomfree with no evidence of recurrent CBDS. There was no mortality.

Conclusion: One-stage laparo-endoscopic treatment of cholecysto-choledocholithiasis is safe and effective with a short total procedural time and a short hospital stay.

Key Words: Cholecysto-choledocholithiasis - Laparoscopy - Endoscopic retrograde cholangiography.

\section{Introduction}

THE reported prevalence of Common Bile Duct Stones (CBDS) in patients with symptomatic Gallbladder Stones (GBS) coming for cholecystectomy varies widely in literature ranging between $3.4 \%$

Correspondence to: Dr. Hamdy S. Abdallah, E-Mail: Hamdy.abdallah@med.tanta.edu.eg hamdysedky@hotmail.com and 20\% in different studies [1-9]. Although about one third of these patients will pass their stones spontaneously within 6 week, some patients develop severe and potentially life threatening complications, including ascending cholangitis and gallstone pancreatitis. Therefore, it is recommended to routinely look for and treat choledocholithiasis at the time of cholecystectomy [2].

Several approaches are available for treatment of CBDS including open or Laparoscopic Common Bile Duct Exploration (LCBDE) and laparoendoscopic treatments, either sequential or simultaneous [10]. The choice between alternative treatment options should consider different variables including patient's physiological status, number, size and location of stones, diameter of CBD, availability of resources and, most importantly, the experience of both the surgical and endoscopic teams [11]

Despite advances in both endoscopic and surgical therapeutics, the management of cholecystocholedocholithiasis continues to present a dilemma to both surgeons and gastroenterologists [12] as a consensus on optimal management does not exist [10]. The aim of this work was to prospectively study the short-term outcomes of the single-stage laparo-endoscopic treatment of cholecystocholedocholithiasis.

\section{Material and Methods}

\section{Study design:}

This study was conducted at the Gastrointestinal and Laparoscopic Surgery Unit, General Surgery Department, Tanta University, Tanta, Egypt during the period from January 2009 to January 2017. Patients with symptomatic GBS and confirmed concomitant CBDS, presenting with biliary pain, calcular obstructive jaundice, ascending cholangitis 
or acute biliary pancreatitis were included in the study. Diagnosis was confirmed by a pre-operative ultrasound (US) and/or Magnetic Resonance Cholangiopancreatography (MRCP) confirming the presence of GBS and CBDS in addition to laboratory evidence of complicated or uncomplicated biliary obstruction. Patients with any of the following conditions were excluded from the study; acute calculus cholecystitis 7 days or more after the disease onset, severe acute pancreatitis, ascending cholangitis with septic shock, CBDS greater than $1.5 \mathrm{~cm}$ diameter, history of upper abdominal surgery, no endoscopic access to the biliary system, uncorrectable coagulopathy, contraindication to laparoscopic surgery and American Society of Anesthesiology (ASA) class IV and V. An informed written consent was obtained from every patient and the study protocol was approved by the "Research Ethics Committee" of the Faculty of Medicine Tanta University.

\section{Intervention:}

The procedure started by standard LC. Calot's triangle was dissected, the cystic artery was identified, clipped and divided, the Cystic Duct (CD) was clipped as high as possible and a small incision was made in the CD distal to the clip. Catheterization of the $\mathrm{CD}$ was performed using a ureteric catheter followed by injection of diluted Urographin to obtain an Intraoperative Cholangiogram (IOC). If the IOC showed no stones with free flow of the contrast into the duodenum (normal IOC), cholecystectomy was completed and the procedure was concluded. If, on the other hand, IOC confirms the presence of CBDS, then, a decision to perform Endoscopic Retrograde Cholangiography (ERC) was taken. Rendezvous technique was not used. ERC was performed by a consultant gastroenterologist experienced in endoscopic biliary interventions after repositioning the patient to the semiprone position. After cannulation of the CBD with a sphincterotome, diluted Urografin was injected into the CBD to obtain an ERC. After identifying the CBDS, Endoscopic Sphincterotomy (ES) was performed. A suitable biliary Fogarty catheter or a Dormia basket was used to retrieve the stones. An occlusion cholangiography was finally performed to confirm clearance of the CBD of stones. In patients with significant papillary stricture or post-sphincterotomy papillary edema, a biliary stent was left in place. Indomethacin $50 \mathrm{mg}$ rectal suppository was used routinely once immediately post-operatively (PO). Liver Function Tests (LFTs) were performed weekly starting one week after surgery till they were normalized. Clinical assessment and abdominal US examination were repeated at 1 and 6 months PO and if all were normal, follow-up was ended.

The following data were recorded: The success rate of IOC, the frequency of CBDS on IOC, operative time, ERC cannulation and stone retrieval rate, endoscopic time, total procedural time, intraoperative and post-operative surgical or endoscopic complications and post-operative hospital stay, readmission or intervention, perioperative mortality and recurrence of CBDS.

\section{Statistical analysis:}

The primary end-point was the success/failure of the laparoscopic cholecystectomy and endoscopic clearance of the CBD and secondary end-points included operative and postoperative complications, total procedural time and postoperative hospital stay. Categorical data were expressed as frequencies while metric data were expressed as range and median using the Microsoft Excel 2013 software.

\section{Results}

\section{Pre-operative results:}

The study population included 200 patients; 140 females (70\%) and 60 males (30\%). The patients' ages ranged between 16 and 62 years with a median of 45.3 years. All patients presented with biliary pain with or without vomiting. One hundred eighty-eight patients (94\%) had also calculator biliary obstruction manifesting by jaundice, dark urine and pale stools with or without itching. Thirty two patients $(16 \%)$ had ascending cholangitis with fever, rigors and leucocytosis. Ten patients $(5 \%)$ had mild form of biliary pancreatitis with elevation of serum amylase and lipase and swollen edematous pancreas on abdominal CT without necrosis or complications.

LFTs showed evidence of biliary obstruction including raised serum bilirubin, alkaline phosphatase and gamma glutamyl transpeptidase in all patients. All 32 patients with ascending cholangitis had +ve CRP and leukocytosis. US examinations showed the presence of multiple GBS and dilated intrahepatic and extrahepatic bile ducts in all patients. CBDS were visualized on US examination in the distal CBD in 114 patients (57\%). MRCP confirmed the presence of GBS, dilatation of the bile ducts and the presence of CBDS in all patients. The size of the CBDS ranged between 4 and $15 \mathrm{~mm}$ with a median of $9.1 \mathrm{~mm}$. The diameter of CBD ranged between 9 and $16 \mathrm{~mm}$ with a median diameter of $11.5 \mathrm{~mm}$ (Table 1). 
Table (1): Pre-operative results.

\begin{tabular}{|c|c|c|}
\hline \multirow{2}{*}{$\begin{array}{l}\text { Variable } \\
\text { Sex: }\end{array}$} & \multicolumn{2}{|c|}{ No. of patients (200) (\%) } \\
\hline & & \\
\hline Female & 140 & 70 \\
\hline Male & 60 & 30 \\
\hline \multicolumn{3}{|l|}{ Age (years): } \\
\hline Range & \multicolumn{2}{|c|}{$16-62$} \\
\hline Median & \multicolumn{2}{|c|}{45.3} \\
\hline \multicolumn{3}{|l|}{ Comorbidity: } \\
\hline Child class (A) liver cirrhosis & 24 & 12 \\
\hline Diabetes mellitus & 14 & 7 \\
\hline Hypertension & 20 & 10 \\
\hline \multicolumn{3}{|l|}{ Clinical presentation: } \\
\hline Biliary pain & 200 & 100 \\
\hline Calcular obstructive jaundice & 188 & 94 \\
\hline Ascending cholangitis & 32 & 16 \\
\hline Mild acute pancreatitis & 10 & 5 \\
\hline \multicolumn{3}{|l|}{ Laboratory tests: } \\
\hline Elevated serum bilirubin & 200 & 100 \\
\hline Elevated liver enzymes & 200 & 100 \\
\hline Leukocytosis & 40 & 20 \\
\hline Elevated pancreatic enzymes & 10 & 5 \\
\hline \multicolumn{3}{|l|}{ Imaging: } \\
\hline GB stone and dilated bile ducts & 200 & 100 \\
\hline CBDS on US & 114 & 57 \\
\hline CBDS on MRCP & 200 & 100 \\
\hline Median diameter of CBD (mm) & \multicolumn{2}{|c|}{11.5} \\
\hline Median (mean) no of CBDS & \multicolumn{2}{|c|}{$1(1.7)$} \\
\hline Median size of largest CBDS & \multicolumn{2}{|c|}{9.1} \\
\hline US : Ultrasound. & & \\
\hline GB : Gallbladder. & & \\
\hline CBDS : Common Bile Duct Stone. & & \\
\hline
\end{tabular}

\section{Operative results:}

The procedure started with LC in all patients. In 5 patients $(2.5 \%)$ with ACC, severe inflammation and adhesions precluded safe dissection of Calot's triangle and the procedure was converted to open surgery performing open cholecystectomy and CBD exploration. LC was successfully completed in the remaining 195 patients $(97.5 \%)$. In these patients, IOC was attempted and it was successfully performed in 185 patients $(94.9 \%)$. In 10 patients $(5.4 \%)$, IOC was normal with no filling defect in the CBD which appeared of normal size with free flow of the contrast into the duodenum. In these 10 patients, only LC was performed. In the remaining 175 patients $(94.6 \%)$, IOC confirmed the presence of CBDS.

In 185 patients ( 175 patients with +ve IOC and 10 patients with failed IOC, $92.5 \%$ ), ERC were performed after completing LC. In these patients, the median time of LC was 65 minutes (range 35$120 \mathrm{~min}$ ) and the median operative blood loss was $43 \mathrm{ml}$ (range 20-90). Cannulation of the papilla was successful (after precut in 13 patients) and
ERC showed CBDS in all patients. ES was then performed and stones were removed successfully and completion cholangiography confirmed clearance of the CBD in all patients. The median time of endoscopic procedure was 47 minutes (range $25-55 \mathrm{~min})$. The total procedural time measured from the first skin incision to withdrawal of the endoscope after the ERC ranged between 80 and 160 minutes with median time of 104 minutes. There were no complications related to either the laparoscopic or endoscopic procedures (Table 2).

Table (2): Operative results.

\begin{tabular}{|c|c|c|}
\hline Variable & $\begin{array}{c}\text { No. of patients } \\
\text { (200) }\end{array}$ & $(\%)$ \\
\hline Attempted LC and ERC: & 200 & 100 \\
\hline Open conversion & 5 & 2.5 \\
\hline LC only & 10 & 5 \\
\hline Completed as scheduled & 185 & 92.5 \\
\hline Attempted IOC: & 195 & 100 \\
\hline Failed & 10 & 5.1 \\
\hline Successful & 185 & 94.9 \\
\hline$+\mathrm{ve}$ & 175 & 94.6 \\
\hline$-\mathrm{ve}$ & 10 & 5.4 \\
\hline \multicolumn{3}{|l|}{ LC data: } \\
\hline Time: Range, median (min) & \multicolumn{2}{|l|}{$35-120(65)$} \\
\hline Blood loss: Range, median $(\mathrm{cm})$ & \multicolumn{2}{|l|}{$20-90(43)$} \\
\hline Standard LC: & 179 & 96.8 \\
\hline Subtotal LC & 6 & 3.2 \\
\hline Complications & 0 & 0 \\
\hline \multicolumn{3}{|l|}{ ERC data: } \\
\hline Time: Range, median (min) & \multicolumn{2}{|l|}{$25-55(47)$} \\
\hline Precut & 13 & 7 \\
\hline Sphincterotomy & 185 & 100 \\
\hline +ve ERC & 185 & 100 \\
\hline Balloon dilatation & 35 & 18.9 \\
\hline Clearance rate & 88 & 100 \\
\hline Stent placement & 9 & 4.9 \\
\hline Complications & 0 & 0 \\
\hline
\end{tabular}

Total procedural time: Range, median

80-160 (104)

Operative mortality

$0 \quad 0$

IOC : Intraoperative Cholangiogram.

LC : Laparoscopic Cholecystectomy.

CBDE : Common Bile Duct Exploration.

ERC : Endoscopic Retrograde Cholangiography.

\section{Post-operative results:}

Oral fluids were allowed 4 hours PO and were tolerated well in all patients. One hundred sixtysix patients $(89.7 \%)$ were discharged home 24 hours PO and the remaining 19 patients $(10.3 \%)$ were discharged over the next 2 days. The PO hospital stay ranged between 1 and 3 days with a median of 1 day (mean 1.5 days). No PO complications related to $\mathrm{LC}$ were recorded. Two patient (1.1\%) developed post-ERC bleeding manifesting on the 3 rd PO day as haematemesis, melaena and 
hypovolemic shock. Management of these patients required readmission, blood transfusion and endoscopic control of the bleeder. Although pancreatic enzymes showed transient increase in 26 patients (14.1\%), none of them developed clinical pancreatitis. LFTs were normalized in all patients within the 3 weeks PO. It was possible to re-assess all patients at 1 month and 160 patients $(86.5 \%)$ at 6 months follow-up and all assessed patients were symptom-free with no evidence of recurrent CBDS on laboratory or radiologic assessment. No mortality was encountered in this study (Table 3 ).

Table (3): Post-operative results.

\begin{tabular}{lc}
\hline Variable & No. of patients $(\%)$ \\
\hline Post-operative hospital stay (days): & $1-3$ \\
$\quad$ Range & 1 \\
Mean & 1.5 \\
Median & \\
Normalization of liver function (weeks): & $1-3$ \\
Range & 2 \\
Median & \\
PO complications: & $2(1.1)$ \\
Post-ERC bleeding & $26(14)$ \\
Elevated pancreatic enzymes & $0(0)$ \\
Clinical pancreatitis & \\
1 month follow-up: & $185(100)$ \\
No of patients & $0(\mathbf{O})$ \\
Recurrent CBDS & $0(\mathbf{O})$ \\
Mortality & \\
months follow-up: & $160(86.5)$ \\
No of patients & $0(\mathbf{O})$ \\
Recurrent CBDS &
\end{tabular}

ERC: Endoscopic Retrograde Cholangiography.

\section{Discussion}

In the era of open cholecystectomy, when IOC confirms the presence of CBDS, CBD exploration and $\mathrm{T}$-tube insertion or internal biliary drainage was performed [13]. With the advent of laparoscopy and endoscopy and standardization of LC as the gold standard treatment of symptomatic GBS, there was a shift from the open surgical management of CBDS to ERCP performed before or after LC [14] With advances in laparoscopic procedures, LCBDE emerged as a one-stage, minimally invasive therapeutic option. However, because this approach is technically demanding, it was performed only in few specialized centers [15]. With more treatment options at hand, came the debate of one versus two-stage management of CBDS [16]. The aim of the current study was to evaluate the clinical outcomes of one-stage laparo-endoscopic approach for the management of symptomatic pre-operatively confirmed cholecysto-choledocolithiasis.

The results of this study show that one-stage laparo-endoscopic approach for the management of symptomatic CBDS is associated with a high success rate with a low overall complication rate, a short total procedural time and a short postoperative hospital stay. Our results are supported by several other reports including systematic reviews and meta-analyses [17-25]. A recent metaanalysis was published in 2017 by Tan et al., comparing the outcomes of one-stage versus twostage laparo-endoscopic approaches for the management of pre-operatively diagnosed CBDS. The rate of CBD clearance was equal for both approaches $(93 \%$ vs. $92 \%, p=0.60)$. The rate of post-ERC pancreatitis and the overall morbidity were lower for Intra-Operative Endoscopic Sphincterotomy (IOES) compared to Pre-Operative Endoscopic Sphincterotomy (POES). Also, the PO hospital stay was shorter in the IOES compared to POES. The authors concluded that IOES is a better option than POES in the management of pre-operatively diagnosed CBD [26]. González et al., compared 3 different approaches for CBDS management; LC + ERC, ERC followed by LC during the same hospital admission and LC+LCBDE. There were no significant differences in success rates of ductal stone clearance, but retained stone, PO complications and length of hospital stay were better in the 1 st group [27]

The reported risks of ERC as a diagnostic procedure include pancreatitis (1-30\%), pancreatic necrosis $(0.3-0.6 \%)$, and mortality $(0.4 \%)$ [28]. One of the major advantages of the one-stage approach is the avoidance of ERC in the case IOC excludes the presence of CBDS. Patients stratified as high risk of heaving CBDS based on clinical, laboratory, and imaging indicators, when underwent ERC were found to have CBDS only $32 \%$ of the time [29] Other advantages of the one-stage approach include shorter hospital stay and reduced costs, higher patients' acceptance and compliance and hence decreased drop-outs [30-32]. Moreover, IOES eliminates the possibility of recurrent CBDS during the interval between ERC and LC in the 2-stage approach (some authors recommend 6-weeks interval) [33] .

When performing one-stage LC and ERC, starting with LC has other several advantages. It avoids the technical difficultly caused by bowel distended with air insufflated during ERC when performed 1 st, allows endoscopic removal of any stone that may inadvertently drop from the gallbladder to the 
CBD during laparoscopy and, finally, if LC fails; the procedure can be converted to open cholecystectomy and CBD exploration instead of performing successful ERC then converting a failed LC to open cholecystectomy.

To confirm the diagnosis of CBDS pre- operatively, MRCP was obtained routinely for all patients. The pre-operative confirmation of CBDS in this study permitted easer coordination between both surgical and endoscopic teams. Our observations is shared by other authors [23] who also suggested that one of the limiting factors in accepting the one-stage LC and ERC is the difficulty of coordination between both teams [24]

Several recent studies indicate that single-stage laparoscopic management of CBDS might be the preferred option in established centers especially if the patient has multiple stones with a dilated CBD [11,34-37]. Advocates of this approach argue that it does damage the sphincter of Oddi, which is proposed to result in cholangitis and recurrence of CBDS. However, since LCBDE is a technically challenging procedure, if laparoscopic experience is limited, CBDS are better removed endoscopically. Moreover, LCBDE may not be the preferred option in patients presenting with cholangitis, because of the possibility of peritoneal contamination.

The overall rate of post-ERC complication varies in different studies with reported rates of $5 \%, 6.8 \%, 7.9 \%,[38-40]$. In a prospective study of 2,347 patients from 17 institutions, $9.8 \%$ had postERCP complications, with post-ERC pancreatitis (5.4\%) and hemorrhage (2\%) being the most common [40]. Post-ERC pancreatitis is defined as a new-onset or worsening abdominal pain with the elevation of serum amylase of 3 or more times the upper limit of normal at 24 hours post-procedure and the need for more than 2 days of pancreatitisrelated hospitalization [41]. In our study, pancreatic enzymes showed transient increase in 13 patients (14.8\%), but none of them developed clinical pancreatitis. This outcome is similar to that reported by other authors who noted that asymptomatic elevation of serum amylase is a common occurrence after ERCP while the incidence of clinically significant post-ERC pancreatitis ranged from 1$15.7 \%$ [42-45].

\section{Conclusion:}

One-stage laparo-endoscopic treatment of cholecysto-choledocholithiasis is safe and effective with a short total procedural time and a short hospital stay.
"Disclosure statement":

- The authors did not receive any fund to conduct this study.

• "No competing financial interests exist".

\section{References}

1- COLLINS C., MAGUIRE D., IRELAND A., et al.: A prospective study of common bile duct calculi in patients undergoing laparoscopic cholecystectomy: Natural history of choledocholithiasis revisited Ann. Surg., 239: 28-33, 2004

2- AL-KHAFFAF B., PARKIN E. and FLOOK D.: Endoscopic retrograde cholangiopancreatography prior to laparoscopic cholecystectomy: A common and potentially hazardous technique that can be avoided. Arch. Surg., 146: 329-33, 2011.

3- FIORE N.F., LEDNICZKY G., WIEBKE E.A., et al.: An analysis of perioperative cholangiography in one thousand laparoscopic cholecystectomies. Surgery, 122: 817-21, 1997.

4- PETELIN J.: Laparoscopic common bile duct explorations. Surg. Endosc., 17: 1705-15, 2003.

5- SANTAMBROGIO R., BIANCHI P., OPOCHER E., et al.: Prevalence and laparoscopic ultrasound patterns of choledocholithiasis and biliary sludge during cholecystectomy. Surg. Laparosc. Endosc. Percutan. Tech., 9: 12934, 1999.

6- KATZ D., NIKFARJAM M., SFAKIOTAKI A. and CHRISTOPHI C.: Selective endoscopic cholangiography for the detection of common bile duct stones in patients with cholelithiasis. Endoscopy, 36: 1045-9, 2004.

7- MENEZES N., MARSON L.P., DEBEAUX A.C., et al.: Prospective analysis of a scoring system to predict choledocholithiasis. Br. J. Surg., 87: 1176-81, 2000.

8- VIDEHULT P., SANDBLOM G. and RASMUSSEN I.C.: How reliable is intraoperative cholangiography as a method for detecting common bile duct stones? A prospective population-based study on 1,171 patients. Surg. Endosc., 23: 304-12, 2009.

9- BORZELLINO G., RODELLA L., SALADINO E., et al.: Treatment for retrieved common bile duct stones during laparoscopic cholecystectomy: The rendezvous technique. Arch. Surg., 145: 1145-9, 2010.

10- SHARMA A., DAHIYA P., KHULLAR R., et al.: Management of Common Bile Duct Stones in the Laparoscopic Era. Indian J. Surg., 74 (3): 264-9, 2012.

11- SHOJAIEFARD A., ESMAEILZADEH M., GHAFOURI A., et al.: Various techniques for the surgical treatment of common bile duct stones: A meta review. Gastroenterology research and practice, 840208, 2009.

12- SHELTON J., KUMMEROW K., PHILLIPS S., et al.: An urban-rural blight? Choledocholithiasis presentation and treatment. J. Surg. Res., 173: 193-7, 2012.

13- GIRARD R.M. and MORIN M.: Open cholecystectomy: Its morbidity and mortality as a reference standard. Can J. Surg., 36: 75-80, 1993. 
14- CHANG L., LO S., STABILE B.E., et al.: Pre-operative versus post-operative endoscopic retrograde cholangiopancreatography in mild to moderate gallstone pancreatitis: A prospective randomized trial. Ann. Surg., 231: 82-7, 2000.

15- PETELIN J.B.: Surgical management of common bile duct stones. Gastrointest Endosc., 56 (Suppl): 183-9, 2002.

16- La GRECA G., BARBAGALLO F., SOfiA M., et al.: Simultaneous laparoendoscopic rendezvous for the treatment of cholecystocholedocholithiasis. Surg. Endosc., 24: 769-80, 2010.

17- MALLICK R., RANK K., RONSTROM C., et al.: Singlesession laparoscopic cholecystectomy and ERCP: A valid option for the management of choledocholithiasis. Gastrointest. Endosc., 84: 639-45, 2016.

18-ZANG J.F., ZHANG C. and GAO J.Y.: Endoscopic retrograde cholangiopancreatography and laparoscopic cholecystectomy during the same session: Feasibility and safety. World J. Gastroenterol., 19: 6093, 2013.

19- KALIMI R., COSGROVE J.M., MARINI C., et al. Combined intraoperative laparoscopic cholecystectomy and endoscopic retrograde cholangiopancreatography: Lessons from 29 cases. Surg. Endosc., 14: 232-4, 2000.

20- EL-GEIDIE A.A.: Laparoendoscopic management of concomitant gallbladder stones and common bile duct stones: What is the best technique? Surg. Laparosc. Endosc. Percutan. Tech., 21: 282-7, 2011.

21- GHAZAL A.H., SOROUR M.A., EL-RIWINI M., et al.: Single-step treatment of gallbladder and bile duct stones: A combined endoscopic-laparoscopic technique. Int. J. Surg., 7: 338-46, 2009.

22- ENOCHSSON L., LINDBERG B., SWAHN F., et al.: Intraoperative endoscopic retrograde cholangiopancreatography (ERCP) to remove common bile duct stones during routine laparoscopic cholecystectomy does not prolong hospitalization: A 2-year experience. Surg. Endosc., 18: 367-71, 2004.

23- EL GEIDIE A.A.: Single-session minimally invasive management of common bile duct stones. World J. Gastroenterol., 20: 15144-52, 2014.

24- WILD J.L., YOUNUS M.J., TORRES D., et al.: Sameday combined endoscopic retrograde cholangiopancreatography and cholecystectomy: Achievable and minimizes costs. J. Trauma Acute Care Surg., 78: 503-7, 2015.

25- PRASSON P., BAI X., ZHANG Q., et al.: One-stage laproendoscopic procedure versus two-stage procedure in the management for gallstone disease and biliary duct calculi: A systemic review and meta-analysis. Surg. Endosc. Surg. Endosc., 30 (8): 3582-90, 2016.

26- TAN C., OCAMPO O., ONG R. and TAN K.S.: Comparison of one stage laparoscopic cholecystectomy combined with intra-operative endoscopic sphincterotomy versus two-stage pre-operative endoscopic sphincterotomy followed by laparoscopic cholecystectomy for the management of preoperatively diagnosed patients with common bile duct stones: A meta-analysis. Surg. Endosc., 2017.

27- GONZÁLEZ J.E.B., PEÑA R.T., TORRES J.R., et al.: Endoscopic versus laparoscopic treatment for choledo- cholithiasis: A prospective randomized controlled trial. Endos. Internat. Open, 04: E1188-E1193, 2016.

28- THAM T.C., LICHTENSTEIN D.R., VANDERVOORT J., et al.: Role of endoscopic retrograde cholangiopancreatography for suspected choledocholithiasis in patients undergoing laparoscopic cholecystectomy. Gastrointest Endosc., 47: 50-6, 1998.

29- DAVIS W.Z., COTTON P.B., ARIAS R.S., et al.: ERCP and sphincterotomy in the context of laparoscopic cholecystectomy; academic and community practice patterns and results. Am. J. Gastroenterol., 92: 597-601, 1997.

30- SACCOMANI G., DURANTE V., MAGNOLIA M.R., et al.: Combined endoscopoic treatment for cholelithiasis associated with choledhocholithiasis. Sure. Endosc., 19 (7): 910-4, 2005.

31- HONG D.F., XIN Y. and CHEN D.W.: Comparison of laparoscopic cholecystectomy combined with intraoperative endoscopic sphincterotomy and laparoscopic exploration of the common bile duct for cholecystocholedocholithiasis. Sure. Endosc., 20 (3): 424-7, 2006.

32- DEL RIO P., DELL'ABATE P., LABONIA D., SALMAN B. and YILMAZ U: Choledocholithiasis and endolaparoscopic rendezvous. Analysis of 59 consecutive cases. Ann. Ital. Chir., 82 (3): 221-449, 2011.

33- LAU J.U., LEOW C.K., FUNG T.M., et al.: Cholecystectomy or gallbladder in situ after endoscopic sphincterotomy and bile duct stone removal in Chinese patients. Gastroenterology, 130 (1): 96-103, 2006.

34- YACHIMSKI P. and POULOSE B.K.: ERCP vs laparoscopic common bile duct exploration for common bile duct stones: Are the 2 techniques truly equivalent? Arch. Surg., 145: 795; author reply 795-6, 2010.

35- HANIF F., AHMED Z., ABDEL SAMIE M., et al.: Laparoscopic transcystic bile duct exploration: The treatment of first choice for common bile duct stones. Surg. Endosc., 24: 1552-6, 2010.

36- ZHANG W., XU G., HUANG Q., et al.: Treatment of gallbladder stone with common bile duct stones in the laparoscopic era. BMC Surgery, 15: 7-13, 2015.

37- PAGANINI A.M., GUERRIER M., SARNARI J., et al.: Thirteen years experience with laparoscopic transcystic common bile duct exploration for stones Effectiveness and long-term results. Surg. Endosc., 21: 34-40, 2007.

38- WILLIAMS E.J., TAYLOR S., FAIRCLOUGH P., et al.: Risk factors for complication following ERCP; results of a large-scale, prospective multicenter study. Endoscopy, 39 (9): 793-801, 2007.

39- ANDRIULLI A., LOPERFIDO S., NAPOLITANO G., et al.: Incidence rates of post-ERCP complications: A systematic survey of prospective studies. Am. J. Gastroenterol., 102 (8): 1781-8, 2007.

40- WANG P., LI Z.S., LIU F., et al.: Risk factors for ERCPrelated complications: A prospective multicenter study. Am. J. Gastroenterol., 104 (1): 31-40, 2009.

41- BARTHET M., LESAVRE N., DESJEUX A., et al.: Complications of endoscopic sphincterotomy: Results from a single tertiary referral center. Endoscopy, 34 (12): 991-7, 2002. 
42- COTTON P.B., LEHMAN G., VENNES J., et al.: Endoscopic sphincterotomy complications and their management: An attempt at consensus. Gastrointest. Endosc., 37 (3): 383-93, 1991.

43- FREEMAN M.L., DiSARIO J.A., NELSON D.B., et al.: Risk factors for post-ERCP pancreatitis: A prospective, multicenter study. Gastrointest Endosc., 54 (4): 425-34, 2001.
44- COTTON P.B., GARROW D.A., GALLAGHER J., et al.: Risk factors for complications after ERCP: A multivariate analysis of 11,497 procedures over 12 years. Gastrointest. Endosc., 70 (1): 80-8, 2009.

45- FREEMAN M.L., NELSON D.B., SHERMAN S., et al.: Complications of endoscopic biliary sphincterotomy. $\mathrm{N}$. Engl. J. Med., 335 (13): 909-18, 1996.

\section{علاج حصوات الحويصلة الصفراوية والقنوات الصفراوية

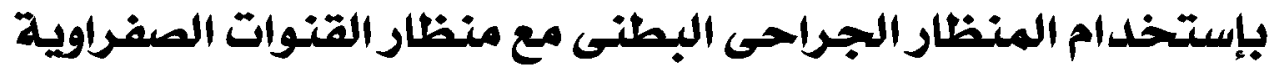

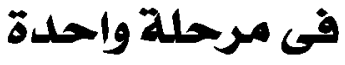

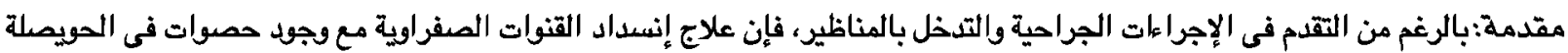

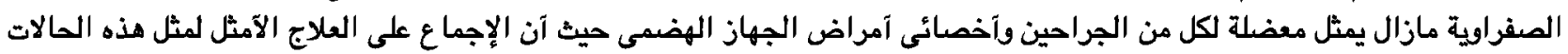

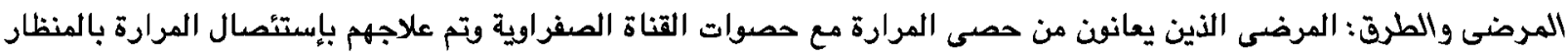

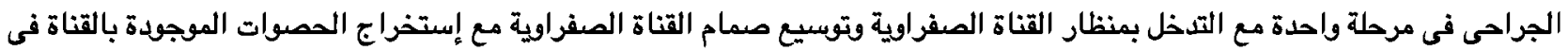

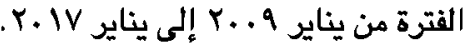

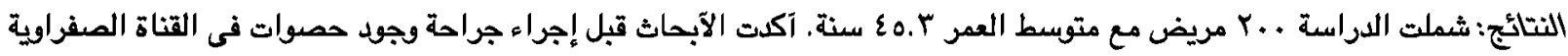

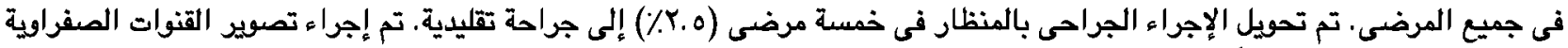

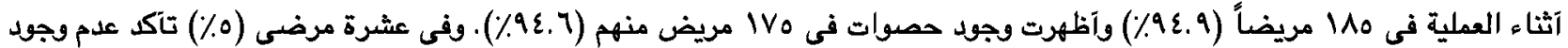

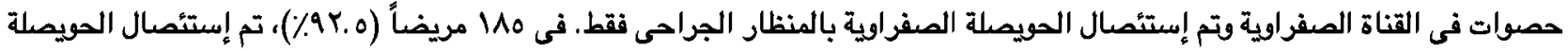

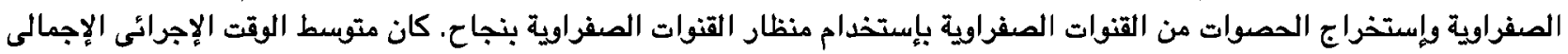

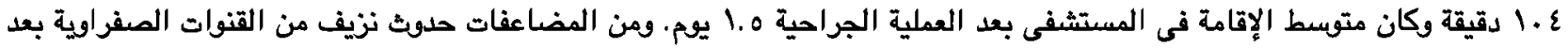

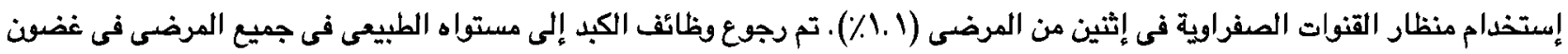

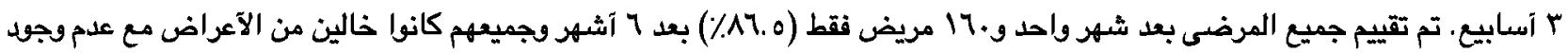
دليل على حصوات قناة صفراوية متكررة. لم يكن هناك وفيات.

الإستتاج: يعتبر العلاج الجراحى بالمنظار فى مرحلة واحدة مع منظار القناة الصفراوية آمناً وفعالاً مع فترة إجرائية قصيرة وإقامة قصيرة 